\title{
Targeted therapies in small cell lung cancer (Review)
}

\author{
HONG-YANG LU, XIAO-JIA WANG and WEI-MIN MAO \\ Zhejiang Key Laboratory of Diagnosis and Treatment Technology on Thoracic Oncology (Lung and Esophagus), \\ Zhejiang Cancer Hospital, Hangzhou, Zhejiang 310022, P.R. China
}

Received March 21, 2012; Accepted June 29, 2012

DOI: $10.3892 / \mathrm{ol} .2012 .791$

\begin{abstract}
Lung cancer is the leading cause of cancer-related mortality. Small cell lung cancer (SCLC) accounted for $12.95 \%$ of all lung cancer histological types in 2002. Despite trends toward modest improvement in survival, the outcome remains extremely poor. Chemotherapy is the cornerstone of treatment in SCLC. More than two-thirds of patients who succumb to lung cancer in the United States are over 65 years old. Elderly patients tolerate chemotherapy poorly and need novel therapeutic agents. Targeted drugs have less toxicity than chemotherapy drugs, but no targeted agents have been approved for use in the treatment of SCLC patients to date. Certain new targeted agents, including gefitinib, bevacizumab and Bcl-2 inhibitors, offer a promise of improved outcomes, however negative results are more commonly reported than positive. This review focuses on targeted therapies in SCLC.
\end{abstract}

\section{Contents}

1. Introduction

2. Growth factor receptor inhibitors

Correspondence to: Dr Hong-Yang Lu, Zhejiang Key Laboratory of Diagnosis and Treatment Technology on Thoracic Oncology (Lung and Esophagus), Zhejiang Cancer Hospital, Banshan Bridge, 38 Guangji Road, Hangzhou, Zhejiang 310022, P.R. China

E-mail: zjzlluhongyang@163.com

Abbreviations: SCLC, small cell lung cancer; VALSG, Veterans Administration Lung Study Group; EGFR, epidermal growth factor receptor; $\mathrm{LD}$, limited-stage disease; $\mathrm{ED}$, extensive-stage disease; NSCLC, non-small cell lung cancer; RT-PCR, reverse transcription polymerase chain reaction; PS, performance status; VEGF, vascular endothelial growth factor; CRT, chemoradiation; CR, complete response; $\mathrm{PR}$, partial response; $\mathrm{SD}$, stable disease; $\mathrm{DCR}$, disease control rate; PFS, progression-free survival; OS, overall survival; ORR, objective response rate; MST, median survival time; TTP, time-to-progression; MMP, matrix metalloproteinase; ASCO, American Society of Clinical Oncology; mTOR, mammalian target of rapamycin; AE, adverse event

Key words: small cell lung cancer, targeted therapy, epidermal growth factor receptor, vascular endothelial growth factor, apoptosis, gene
3. Angiogenesis inhibitors

4. Apoptosis promoters

5. Other agents

6. Discussion

\section{Introduction}

The most commonly diagnosed types of cancer worldwide are lung (1.61 million, $12.7 \%$ of the total), breast (1.38 million, $10.9 \%)$ and colorectal cancers (1.23 million, 9.7\%). The most common causes of cancer mortality are lung (1.38 million mortalities, $18.2 \%$ of the total), stomach $(738,000,9.7 \%)$ and liver cancer $(696,000,9.2 \%)(1)$. The proportion of small cell lung cancer (SCLC; among all lung cancer histological types) decreased from $17.26 \%$ in 1986 to $12.95 \%$ in 2002 . The proportion of women with SCLC increased from $28 \%$ in 1973 to $50 \%$ in 2002 . There has been a modest but statistically significant improvement in two- and five-year survival. SCLC is nearly universally smoking-related. Possible explanations for the decreasing incidence of SCLC include the decrease in the percentage of smokers and the change to low-tar filter cigarettes. Despite trends toward modest improvement in survival, the outcome remains extremely poor (2).

SCLC is most commonly staged by the Veterans Administration Lung Study Group (VALSG) staging system (3). This system classifies patients as having limited- or extensive-stage disease (LD and ED, respectively). LD is defined as disease confined to one hemithorax, in the absence of a malignant effusion, with disease that can be encompassed in one radiation port. Disease that does not meet these criteria is defined as ED. The TNM staging system is also used for SCLC, especially for patients receiving surgical treatment (4). Approximately one-third of patients diagnosed with SCLC present with LD, which has a median survival time (MST)of 15-20 months. A response to combination chemotherapy is achieved by $80-90 \%$ of LD patients, with or without thoracic radiation (5). Of patients with ED SCLC, 60-80\% respond to chemotherapy, the MST is eight to ten months and the one- and two-year survival rates are 35 and $10 \%$, respectively (6). SCLC is characterized by its rapid doubling time and high growth fraction. SCLC has a propensity for chemosensitivity, for early hematogenous spread and for association with paraneoplastic syndromes. Chemotherapy is the cornerstone of treatment.

More than two-thirds of patients who succumb to lung cancer in the United States are over 65 years old (7). Elderly 
patients tolerate chemotherapy poorly and need novel therapeutic agents. A targeted therapy is a type of medication that blocks the growth of cancer cells by interfering with specific targeted molecules needed for carcinogenesis and tumor growth, rather than by simply interfering with rapidly dividing cells (as with traditional chemotherapy). Targeted drugs have less toxicity than chemotherapy drugs. Certain new targeted agents offer a promise of improved outcomes and negative results are more commonly reported than positive. This review focuses on targeted therapy in SCLC.

\section{Growth factor receptor inhibitors}

Gefitinib. Epidermal growth factor receptor (EGFR) tyrosine kinase inhibitor may be used as a first-line therapy in patients with advanced non-SCLC (NSCLC) with EGFR mutations (8-12). The results of the INTEREST trial (13) suggest that gefitinib provides similar overall survival (OS) to docetaxel in patients across a broad range of clinical subgroups and EGFR biomarkers, including mutation status, may additionally identify which patients are likely to gain greatest progression-free survival (PFS) and objective response rate (ORR) benefit from gefitinib. Tanno et al evaluated the effect of gefitinib against the SCLC cell lines NCI-H82, NCI-H209, NCI-H510, NCI-H526 and NCI-H660. The authors found that gefitinib inhibited the phosphorylation of ERK $1 / 2$ by EGF addition in cell lines with detectable and undetectable EGFR expression, and suggested that gefitinib is potentially effective against cancers with low EGFR expression, including SCLC (14). Gefitinib has not been recommended for use in SCLC, but some case reports on this subject have been published. A case study concerning a Japanese patient with gefitinib-responsive SCLC reported that the patient had a deletion in exon 19 of EGFR (15). Moreover, another case study also reported that a never-smoking American SCLC patient with an EGFR mutation responded to erlotinib and gefitinib (16). In China, there has also been a case report of an SCLC patient responding to gefitinib, but the status of the mutation is unknown (17). A phase II trial concerning gefitinib in patients with chemosensitive and chemorefractory relapsed SCLC has been performed. A total of 12 patients $(63 \%)$ had chemosensitive disease and seven $(37 \%)$ had chemorefractory disease. Two patients had stable disease (SD) and 17 had progressive disease (PD). This study failed to demonstrate a benefit from the use of gefitinib in SCLC patients (18).

EGFR mutation is important for gefitinib and erlotinib therapy in advanced NSCLC, especially in first-line therapy, and it may also be significant in SCLC. Shiao et al (19) searched for EGFR mutations in 76 SCLC specimens using reverse transcription polymerase chain reaction (RT-PCR) and direct sequencing. Two specimens (2.6\%) tested positive for the EGFR mutation, both deletions in exon 19. The specimens in this study included ten computed tomography-guided biopsy, 17 echo-guided aspiration, 37 echo-guided biopsy, one surgical lobectomy and 11 malignant pleural effusion specimens. Another study (20) analyzed 122 cases of SCLC patients, including 102 specimens obtained by biopsy and 20 from surgical resection, detected by standard RT-PCR coupled with direct sequencing. EGFR mutations were detected in five SCLCs (4\%). The patients were mainly light smokers and were in the histological combined subtype. In three tumors of the combined SCLC subtype, both components of adenocarcinoma and SCLC had an EGFR mutation. A partial response (PR) was achieved in a patient (with an EGFR mutation) who was treated with gefitinib. The patients with EGFR mutation were more likely to have SCLC combined with adenocarcinoma compared with the whole SCLC population. We also detected EGFR exon 19 and 21 mutations of 40 SCLC patients who received surgical treatment in Zhejiang Cancer Hospital (Hangzhou, China) between 1998 and 2010 using xTAG technology. Two of 40 cases were found to have a mutation in EGFR exon 19. One patient with EGFR exon 19 mutation was a female non-smoking patient with SCLC combined with adenocarcinoma, and the other was a male smoker with SCLC combined with squamous cell carcinoma. The EGFR mutation is rare in SCLC patients, and EGFR mutation may occur more frequently in combined SCLCs than conventional patients (21). Of SCLC patients who undergo surgical resection, $28 \%$ have combined SCLC, and surgical specimens may more accurately reflect the clinicopathological status (22). The low incidence of EGFR exon 19 or 21 mutations may be the cause of the negative result of the study by Moore et al (18). We suggest that an EGFR tyrosine kinase inhibitor is a suitable selection for SCLCs with EGFR exon 19 or 21 mutation when relapsed following chemotherapy or in patients who cannot tolerant chemotherapy. Further research concerning SCLC and combined SCLC with regard to EGFR mutation should be performed.

Imatinib. With the success of imatinib mesylate (STI571) in the treatment of c-kit expression and mutation in gastrointestinal stromal tumors, its use in SCLC presented a novel molecular therapeutic approach. The activity of imatinib mesylate is related to the mutation of c-kit in exons 9 and 11 in gastrointestinal stromal tumor $(23,24)$. In the trial performed by Johnson et al (25), 19 SCLC patients (9 chemonaïve patients with ED and 10 sensitive relapsed SCLC patients) received $600 \mathrm{mg}$ imatinib on a daily basis. Tumor tissue samples from four $(21 \%)$ of the 19 patients had the KIT receptor (CD117). No objective responses were observed. In another phase II clinical trial (26), 12 patients with SCLC with c-kit expression and PD after one or two previous chemotherapy regimens received imatinib at $400 \mathrm{mg}$ orally twice daily. No responses were observed, and all patients had disease progression by week four. The trial performed by Dy et al (27) also evaluated imatinib for patients with relapsed SCLC with c-kit expression and the result was also negative. Boldrini et al studied 60 SCLC samples to determine the mutations of the coding region of the c-kit gene. The expression of c-kit was demonstrated in $~ 40 \%$ of SCLC samples, and two patients with mutations in exon 9 and three patients with mutations in exon 11 were identified. Kaplan-Meier analysis revealed no prognostic significance of c-kit expression for survival (28). We detected c-kit exons 9 and 11 mutation using a pyrosequencing assay in 36 SCLC patients who received surgical treatment in Zhejiang Cancer Hospital between 1998 and 2010. No mutation of c-kit exon 9 or 11 was detected (29).

Other research has focused on imatinib combined chemotherapy or maintenance following chemotherapy. A phase II trial (30) studied irinotecan, carboplatin and imatinib in 
patients with untreated ED SCLC. A total of 68 patients received carboplatin [area under the concentration-time curve (AUC) of 4 on day 1], irinotecan $\left(60 \mathrm{mg} / \mathrm{m}^{2}\right.$ on days 1,8 and 15$)$ and imatinib (600 mg/day). The treatment cycles were 28 days. Patients remained on imatinib until PD or significant toxicity. The ORR was $66 \%$, median PFS was 5.4 months and MST was 8.4 months. After 1 year, $35 \%$ of the patients were alive. Grade 3/4 hematological toxicities included neutropenia (43\%), anemia (16\%) and thrombocytopenia (9\%). Grade 3 non-hematological toxicities included diarrhea (19\%), fatigue (24\%) and nausea (26\%). Irinotecan, carboplatin and imatinib is a safe and generally well-tolerated regimen in patients with SCLC. However, the addition of imatinib did not improve results from those expected with chemotherapy alone. Another phase II trial concerned imatinib maintenance therapy following irinotecan and cisplatin in patients with c-kit-positive ED SCLC. A total of 14 patients were enrolled and imatinib did not appear to delay disease progression following response to chemotherapy (31).

\section{Angiogenesis inhibitors}

Thalidomide. Tumor growth depends on angiogenesis. Thalidomide has antiangiogenic and immunomodulatory properties. A phase III double-blind, placebo-controlled study (32) on thalidomide in ED SCLC following response to chemotherapy has been performed. A total of 119 patients received two courses of etoposide, cisplatin, cyclophosphamide and 4'-epidoxorubicin (PCDE). Responsive patients who had recovered from chemotherapy toxicity were randomly assigned to receive four additional PCDE cycles plus thalidomide $(400 \mathrm{mg}$ daily) or placebo. A total of 92 patients were randomly assigned to placebo $(n=43)$ or thalidomide $(n=49)$. Patients treated with thalidomide had a longer survival compared with those who received placebo (11.7 vs. 8.7 months, $\mathrm{P}=0.16$ ), although the difference was not statistically significant. Patients with a performance status (PS) of 1 or 2 who received thalidomide had a significantly longer survival $(\mathrm{P}=0.02)$ compared to the patients with a PS of 1 or 2 who received the placebo. Neuropathy occurred more frequently in the thalidomide group compared with the placebo group (33 vs. 12\%). At present, the regimen of PCDE is not commonly used in SCLC and other chemotherapy regimens, including etoposide and cisplatin combined with thalidomide, are warranted.

Vandetanib. ZD6474 (vandetanib) is an oral receptor tyrosine kinase inhibitor which inhibits both vascular endothelial growth factor (VEGF) and EGFR. A phase II study (33) about vandetanib or placebo in SCLC patients following complete response (CR) or PR to induction chemotherapy with or without radiation therapy has been performed. A total of 107 patients were recruited, including 46 cases of LD and 61 cases of ED. Vandetanib patients experienced more toxicities and required more dose modifications for gastrointestinal toxicity and rash. The OS for vandetanib was 10.6 versus 11.9 months for placebo $(\mathrm{P}=0.9)$. Vandetanib failed to demonstrate efficacy as a maintenance therapy for SCLC.

Bevacizumab. Bevacizumab (Avastin) is a humanized monoclonal antibody directed against VEGF. A phase II trial of concurrent chemoradiation (CRT) and bevacizumab in LD SCLC suggested that bevacizumab increases the risk for tracheoesophageal (TE) fistula when administered with and following CRT. Potential mechanisms include enhanced regional tissue injury and impaired mucosal healing (34). A phase II study (35) investigated cisplatin plus etoposide and bevacizumab for previously untreated ED SCLC. A total of 63 patients were treated with bevacizumab $(15 \mathrm{mg} / \mathrm{kg})$ plus cisplatin $\left(60 \mathrm{mg} / \mathrm{m}^{2}\right)$ and etoposide $\left(120 \mathrm{mg} / \mathrm{m}^{2)}\right.$, followed by bevacizumab alone until mortality or disease progression occurred. The 6-month PFS was 30.2\%, the median PFS was 4.7 months and OS was 10.9 months. The ORR was $63.5 \%$ and the most common adverse event (AE) was neutropenia (57.8\%). Only one patient had grade 3 pulmonary hemorrhage. The addition of bevacizumab with cisplatin and etoposide in patients with ED SCLC results in improved PFS and OS relative to historical controls who received this chemotherapy regimen without bevacizumab. This regimen appears to be well tolerated and has a minimal increase in toxicities compared with chemotherapy alone. Another randomized phase II study (36) concerned bevacizumab to cisplatin or carboplatin plus etoposide in previously untreated ED SCLC. Bevacizumab to cisplatin or carboplatin plus etoposide for treatment of ED SCLC improved PFS, with an acceptable toxicity profile. However, no improvement in OS was observed.

A phase II trial (37) evaluated irinotecan, carboplatin and bevacizumab in the treatment of patients with ED SCLC. A total of 51 patients with no prior SCLC chemotherapy, no active brain metastases, no hemoptysis and Eastern Cooperative Oncology Group PS 0-1 were enrolled. Treatment consisted of irinotecan $\left(60 \mathrm{mg} / \mathrm{m}^{2}\right)$ administered intravenously on days 1,8 and 15 , carboplatin $(\mathrm{AUC}=4)$ on day 1 and bevacizumab (10 mg/kg) on days 1 and 15 every 28 days for up to six cycles. Patients with no progression received maintenance bevacizumab. ORR was $84 \%$, median time-to-progression (TTP) was 9.13 months, MST was 12.1 months and the one- and two-year OS rates were 51 and 14\%, respectively. Grade 3/4 toxicity $(\geq 10 \%)$ included neutropenia (39\%), thrombocytopenia (22\%), dehydration (10\%), diarrhea (31\%), fatigue (20\%) and pulmonary symptoms (10\%). No significant bleeding occurred. Another phase II study (38) analyzed cisplatin, irinotecan and bevacizumab for untreated ED SCLC. The results suggest PFS and OS times were longer compared with those of US trials in ED SCLC with the same chemotherapy. Hypertension was associated with improved survival after adjusting for age and PS. The results of a phase II study (39) concerning oral topotecan plus bevacizumab (topo-bev) for second-line treatment of SCLC suggest that the primary efficacy endpoint of improvement in 3-month PFS was not met and that a marginal benefit of this combination cannot be ruled out. The results of another clinical trial (40), which studied paclitaxel plus bevacizumab in patients with chemosensitive relapsed SCLC, suggest that the addition of bevacizumab to paclitaxel does not improve outcomes in these patients.

NGR-hTNF. NGR-hTNF, a selective vascular targeting agent, improves the intratumoral doxorubicin penetration by normalizing tumor vasculature and decreasing tumor interstitial fluid pressure. A phase II trial (41) about NGR-hTNF and doxorubicin in relapsed SCLC was reported at the 2011 
annual meeting of the American Society of Clinical Oncology (ASCO). A total of 28 patients were recruited. NGR-hTNF did not increase doxorubicin-related toxicity. The disease control rate (DCR) was 55\%, including six cases of PR (22\%) and nine cases of SD (33\%), and the median PFS was 3.2 months. Over a median follow-up period of 19.3 months, the 6-month and 1-year ORRs were 49 and 34\%, respectively. By Cox analyses, PFS and OS did not correlate with age, gender, PS or platinum sensitivity, while only the neutrophil-to-lymphocyte ratio was associated with OS (HR, 0.30). Further development of NGR-hTNF plus doxorubicin in platinum-resistant or -sensitive SCLC is of interest.

Cediranib. Cediranib is a highly potent inhibitor of VEGFR-1, -2 and -3 tyrosine kinases. A phase II study (42) evaluated its safety and efficacy in relapsed/recurrent SCLC. The dose of cediranib was $45 \mathrm{mg}$ per os (PO) once a day for the first 12 patients and was reduced to $30 \mathrm{mg} \mathrm{PO}$ once a day for the subsequent patients due to intolerance of the higher dose. Cediranib failed to demonstrate objective responses in recurrent or refractory SCLC at the dose and schedule evaluated.

Sorafenib. Sorafenib is a multiple kinase inhibitor of Raf kinase, VEGFR-2, VEGFR-3 and platelet-derived growth factor receptor (PDGFR) $\beta$ and affects pathways involved in tumor progression and angiogenesis. A phase II trial of sorafenib in platinum-treated ED SCLC patients determined the tumor response rate, toxicity and OS (43). Patients were treated with sorafenib (400 mg PO BID) continuously on a 28-day cycle. Of the 89 patients recruited, 81 were evaluated for toxicity assessment and 79 were evaluated for response. There were no cases of CR, PR was $34 \%$ and SD was $32 \%$. MST was 7 (platinumsensitive) and 5 months (platinum-refractory). Major toxicities included 20 patients $(25 \%)$ with grade 3 dermatological toxicity, $11(14 \%)$ with grade $3 / 4$ flu-like symptoms and nine (11\%) with grade $3 / 4$ metabolic toxicity. A total of 18 patients discontinued treatment due to AEs or side-effects of therapy. Further study of sorafenib in combination with chemotherapy is warranted.

Sunitinib. Sunitinib is a multi-targeted tyrosine kinase inhibitor with direct antitumor and antiangiogenesis activity through targeting PDGFR, VEGFR, KIT and FLT3 receptors. A phase II study of sunitinib in patients with relapsed or refractory SCLC was conducted to evaluate the efficacy and safety of sunitinib (44). Patients received sunitinib (50 mg/day) for four weeks on and two weeks off in a 6-week cycle. A total of 25 patients were enrolled; 24 received treatment and 23 were evaluated for response. The ORR was $9 \%$ and the median PFS and OS were 1.4 and 5.6 months, respectively. Grade 3/4 toxicity for sunitinib included thrombocytopenia $(63 \%)$, neutropenia (25\%), asthenia (8\%) and anorexia (8\%). One or two dose reductions were required by $46 \%$ of patients. This approach does not appear to warrant further clinical study.

A phase II study evaluated irinotecan and carboplatin followed by maintenance sunitinib in the first-line treatment of ED SCLC. Patients received up to 6 cycles of irinotecan $\left(60 \mathrm{mg} / \mathrm{m}^{2}\right)$ on days 1,8 and 15 and carboplatin $(\mathrm{AUC}=4)$ on day 1. Cycles were repeated every 28 days. All patients without progression or intolerable toxicity continued receiving single-agent sunitinib (25 mg orally daily) until progression.
A total of 34 patients were enrolled. The median TTP was 7.6 months and the 6-month ORR was $91 \%$. No grade $3 / 4$ toxicities were observed in the four patients who received sunitinib. Maintenance sunitinib was well tolerated following platinum doublet chemotherapy as first-line treatment for ED SCLC (45). Another clinical trial analyzed combination chemotherapy with sunitinib for untreated ED SCLC. The combination of sunitinib (25 mg/day days 1-14) with standard dose cisplatin and etoposide appeared to cause prolonged neutropenia and an unacceptable rate of treatment-related mortality. This combination of chemotherapy and sunitinib is not recommended, even with growth factor support (46).

Marimastat and BAY 12-9566. Matrix metalloproteinases (MMPs) and their tissue inhibitors are important in processes of tumor growth and morphogenesis. The increased tumoral expression levels of MMP-3, -11 and -14 were found to be independent negative prognostic factors for survival in SCLC (47). Synthetic MMP inhibitors may be effective in SCLC, and some clinical trials have evaluated this. Marimastat (BB2516) inhibits MMP-1, -2, -3, -7 and -9 and BAY 12-9566 inhibits MMP-2, -9 and -3. A prospective randomized double-blind placebo-controlled phase III trial of marimastat following response to first-line chemotherapy in SCLC patients has been reported. There were 532 eligible patients (266 marimastat and 266 placebo). The stage of SCLC was limited for 279 patients $(52 \%)$ and extensive for $253(48 \%)$. The median TTP for the marimastat patients was 4.3 months, compared with 4.4 months for the placebo patients $(\mathrm{P}=0.81)$. The MST for marimastat and placebo patients was 9.3 and 9.7 months, respectively $(\mathrm{P}=0.90)$. Toxicity was generally limited to musculoskeletal symptoms (18\% grade $3 / 4$ for marimastat). Dose modifications for musculoskeletal toxicity were required in 90 patients $(33 \%)$ on the marimastat arm and $87(32 \%)$ permanently stopped marimastat due to toxicity. Treatment with marimastat following induction therapy for SCLC did not result in improved survival and had a negative impact on quality of life (48). Another phase III randomized, placebo-controlled trial (49) examined the role of BAY 12-9566 in NSCLC and SCLC. BAY 12-9566 did not show any advantage in terms of survival and the incidence of AEs was higher in patients who received BAY 12-9566 compared with the placebo. MMPs are likely to play a smaller role in SCLCs and further clinical trials of MMP inhibitors may be not necessary for SCLC.

\section{Apoptosis promoters}

G3139. The overexpression of Bcl-2 is found in the majority of SCLCs and is associated with resistance. G3139 is an antisense oligonucleotide complementary to the mRNA encoding Bcl-2. The suppression of Bcl-2 levels through the use of G3139 may increase the antitumor efficacy. A pilot trial (50) evaluated G3139 and paclitaxel in patients with chemorefractory SCLC. A total of 12 patients with chemorefractory SCLC participated in this pilot trial of paclitaxel combined with G3139. The combination of paclitaxel at $150 \mathrm{mg} / \mathrm{m}^{2}$ and $\mathrm{G} 3139$ at $3 \mathrm{mg} / \mathrm{kg} /$ day was found to be feasible and well tolerated. No objective responses were observed, but two patients had SD, one remaining stable on therapy for $>30$ weeks. This study demonstrates that G3139 may be combined with paclitaxel in a cytotoxic dose range. A 
phase I study (51) of G3139 combined with carboplatin and etoposide in patients with SCLC suggested that the regimen was well tolerated and results in an encouraging response rate and TTP in ED SCLC patients. A 3:1 randomized phase II study (52) was then performed to evaluate carboplatin and etoposide with (arm A) or without (arm B) oblimersen in 56 assessable patients with chemonaïve ED SCLC. The addition of oblimersen to a standard regimen for this disease did not improve any clinical outcome measure. The additional evaluation of this agent in SCLC is not warranted.

$A B T-263$. ABT-263 is a novel BH3 mimetic which binds with high affinity $\left(\mathrm{K}_{\mathrm{i}} \leq 1 \mathrm{nM}\right)$ and inhibits multiple antiapoptotic Bcl-2 proteins. A study (53) concerning the activity of ABT-263 in a panel of SCLC xenograft models suggested that SCLC is a promising area of clinical investigation with this agent. A phase IIa study of ABT-263 in patients with relapsed SCLC was reported at the ASCO 2010 annual meeting. ABT-263 was administered orally at $325 \mathrm{mg}$ once daily, following a 7-day lead-in dose of $150 \mathrm{mg}$, on a 21-day cycle until PD or intolerable toxicity. A total of 39 patients were enrolled, 21 discontinued due to PD, four withdrew consent and 14 remained in the study (four with SD). A total of six patients had dose reductions due to AEs and 11 experienced serious AEs. The most common AEs were diarrhea (43\%), back pain (43\%) and thrombocytopenia (29\%). The most common grade $3 / 4$ AE was thrombocytopenia (29\%). Four patients had dose interruptions due to AEs. This phase II study revealed that ABT-263 has an acceptable safety profile and the evaluation of tumor response is ongoing in the phase II portion (54).

Obatoclax. Obatoclax is a pan-Bcl-2 antagonist. Langer et al (55) reported a randomized phase II study of carboplatin and etoposide with or without pan-Bcl-2 antagonist obatoclax in ED SCLC at the ASCO 2011 annual meeting. A total of 65 patients were randomized and 155 (77 carboplatin, etoposide and obatoclax; 78 carboplatin and etoposide) received treatment. The only grade $3 / 4$ non-hemorrhage AE with $>5 \%$ increase in absolute frequency in the obatoclax arm was somnolence (8 vs. $0 \%$, obatoclax arm vs. carboplatin-etoposide arm). Grade $3 / 4$ febrile neutropenia was rare (5\%, both arms). Grade 3/4 hematological data were similar for each arm (obatoclax arm vs. carboplatin-etoposide arm): anemia, 8 vs. $15 \%$; neutropenia, 61 vs. $58 \%$; and thrombocytopenia, 17 vs. $10 \%$. The obatoclax arm demonstrated a trend for improved ORR, PFS, 12 months survival and OS. Obatoclax markedly decreased the refractory rate to the initial 6 cycles of chemotherapy by $36.5 \%$. Patients with a screening PS of 2 performed poorly in both arms. OS in PS 0-1 patients will be evaluated in a phase III trial comparing carboplatin-etoposide with carboplatin, etoposide and obatoclax (55).

AT-101. AT-101 is an oral, pan-Bcl-2 family protein inhibitor. A phase I/II study of AT-101 in combination with topotecan in patients with relapsed or refractory SCLC following prior platinum-containing first-line chemotherapy was reported at the 2009 ASCO annual meeting (56). A total of 36 patients were enrolled in the study. The recommended phase II dose was AT-101, $40 \mathrm{mg}$ days 1 to 5 with topotecan, $1.25 \mathrm{mg} / \mathrm{m}^{2}$ days 1 to 5 on a 21-day cycle. In the sensitive-relapsed cohort $(n=18)$, there were no CR, three PR, ten SD and four PD. In the refractory cohort $(n=12)$, there were no $C R / P R$, five SD and five PD. The median TTP in the sensitive-relapsed cohort was 17.4 weeks and in the refractory cohort was 11.7 weeks. Additional trials of AT-101 in SCLC are ongoing.

\section{Other agents}

Everolimus. The Akt/mammalian target of rapamycin (mTOR) pathway is frequently activated and plays an important role in SCLC. RAD001 (everolimus) is an orally administered mTOR inhibitor. Kotsakis et al reported a phase II study of RAD001 in previously treated SCLC at the 2009 ASCO annual meeting (57). A total of 40 patients were treated with everolimus (10 mg orally daily) until disease progression. A total of 28 patients received two or more cycles of everolimus, seven received one cycle and five did not complete the first cycle. The best response in 35 evaluated patients was one (3\%) PR (in sensitive relapse), eight (23\%) SD and $26(74 \%)$ PD. DCR at six weeks was $26 \%$. MST was 6.7 months and median TTP was 1.3 months. Grade 3 toxicities included thrombocytopenia $(n=2)$, neutropenia $(n=2)$, infection $(n=2)$, pneumonitis $(n=1)$, fatigue $(n=1)$, elevated transaminases $(n=1)$, diarrhea $(n=2)$ and acute renal failure $(n=1)$. Everolimus was well tolerated but had limited single-agent antitumor activity in unselected previously treated patients with relapsed SCLC. Further evaluation in combination regimens for patients with sensitive relapse may be considered.

BI 2536. BI 2536 is a potent selective inhibitor of polo-like kinase 1 , a regulator of mitotic progression. A clinical phase II trial demonstrated that BI 2536 was well tolerated in relapsed SCLC patients, but revealed no convincing antitumor efficacy. BI 2536 should not be assessed further as a single agent in SCLC (58).

$R 115777$. Ras requires farnesylation before it is able to mediate its proliferative functions. R115777 is an oral, non-peptidomimetic farnesyl transferase inhibitor related to cell proliferation and survival and blocks the activity of farnesylated proteins (e.g. ras) involved in signal transduction. A multi-center phase II study evaluated R115777 in patients with sensitive relapsed SCLC. R115777 was administered in 3-week cycles at a dose of $400 \mathrm{mg}$ orally twice daily for 14 consecutive days followed by seven days off treatment, and 22 patients were enrolled. The trial was terminated as no objective responses were observed in the 20 patients evaluable for response (59).

p53 cancer vaccine. Cells become susceptible to DNA damage and dysregulated cell growth if p53 genes are deleted or mutated. Patients with a p53 mutation may be identified as more likely to be resistant to chemotherapy or radiotherapy (60). On this basis, gene therapies targeting p53 have been explored. A trial evaluated the combination of a p53 cancer vaccine with chemotherapy in patients with ED SCLC. This vaccine, consisting of dendritic cells transduced with the full-length wild-type p53 gene, was delivered via an adenoviral vector. A total of 29 patients with ED SCLC were vaccinated repeatedly at 2 -week intervals. Most of the 
Table I. Completed phase III randomized trials of targeted therapies in SCLC.

\begin{tabular}{|c|c|c|c|c|c|}
\hline Author (ref.) & Study population & Treatment & $\begin{array}{l}\text { No. } \\
\text { patients }\end{array}$ & $\begin{array}{c}\text { OS } \\
\text { (months) }\end{array}$ & Comments \\
\hline $\begin{array}{l}\text { Pujol JLet al } \\
(32)\end{array}$ & $\begin{array}{l}\text { ED SCLC after response } \\
\text { to chemotherapy }\end{array}$ & $\begin{array}{l}\text { Thalidomide } \\
\text { vs. control }\end{array}$ & $\begin{array}{c}49 \\
\text { vs. } 42\end{array}$ & $\begin{array}{c}11.7 \text { vs. } 8.7 \\
P=0.16\end{array}$ & $\begin{array}{l}\text { Negative, but thalidomide had a } \\
\text { significantly longer survival in } \\
\text { patients with a PS of } 1 \text { or } 2\end{array}$ \\
\hline $\begin{array}{l}\text { Shepherd FA et al } \\
\text { (48) }\end{array}$ & $\begin{array}{l}\text { Response to first-line chemo- } \\
\text { therapy in SCLC patients }\end{array}$ & $\begin{array}{l}\text { Marimastat } \\
\text { vs. control }\end{array}$ & $\begin{array}{c}266 \\
\text { vs. } 266\end{array}$ & $\begin{array}{c}9.3 \text { vs. } 9.7 \\
P=0.90\end{array}$ & Negative \\
\hline $\begin{array}{l}\text { Rigas JR et al } \\
\text { (49) }\end{array}$ & Patients in CR and PR & $\begin{array}{l}\text { BAY 12-9566 } \\
\text { vs. control }\end{array}$ & 327 & $\begin{array}{c}3.2 \text { vs. } 5.3^{\mathrm{a}} \\
\mathrm{P}=0.05\end{array}$ & Negative \\
\hline $\begin{array}{l}\text { Bottomley A et al } \\
\text { (63) }\end{array}$ & $\begin{array}{l}\text { Responding patients with } \\
\text { LD SCLC }\end{array}$ & $\begin{array}{l}\text { Bec } 2 \\
\text { vs. control }\end{array}$ & 515 & $\begin{array}{c}14.3 \text { vs. } 16.4 \\
P=0.28\end{array}$ & $\begin{array}{l}\text { Negative but a trend toward pro- } \\
\text { longed survival in patients who } \\
\text { developed a humoral response }\end{array}$ \\
\hline
\end{tabular}

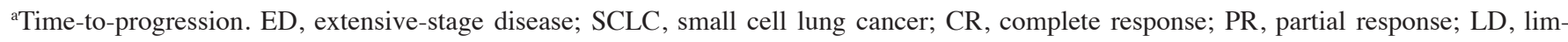
ited-stage disease; PS, performance status; OS, overall survival.

Table II. Phase II trials of targeted therapies in SCLC with negative results.

\begin{tabular}{|c|c|c|c|}
\hline Author (ref.) & Study population & No. patients & Treatment \\
\hline Moore AM et al (18) & Chemosensitive and chemorefractory relapsed & 19 & Gefitinib alone \\
\hline Johnson BE et al (25) & Chemonaïve with ED and sensitive relapse & 19 & Imatinib alone \\
\hline Krug LM et al (26) & $\begin{array}{l}\text { C-kit expression and progressive after } 1 \text { or } 2 \\
\text { previous chemotherapy regimens }\end{array}$ & 12 & Imatinib alone \\
\hline Dy GK et al (27) & Relapsed SCLC with c-kit expression & 29 & Imatinib alone \\
\hline Spigel DR et al (30) & Untreated ED & 68 & $\begin{array}{l}\text { Irinotecan and carboplatin with } \\
\text { imatinib }\end{array}$ \\
\hline Schneider BJ et al (31) & $\begin{array}{l}\text { ED SCLC with c-kit-positive and therapy } \\
\text { after irinotecan and cisplatin }\end{array}$ & 14 & Maintenance with imatinib \\
\hline Arnold AM et al (33) & After CR or PR to induction chemotherapy & 107 & $\begin{array}{l}\text { Maintenance with imatinib or } \\
\text { placebo }\end{array}$ \\
\hline Waterhouse DM et al (39) & Second-line treatment & 50 & Oral topotecan plus bevacizumab \\
\hline Jalal S et al (40) & Chemosensitive relapsed & 34 & Paclitaxel plus bevacizumab \\
\hline Ramalingam SS et al (42) & Relapsed/recurrent & 25 & Cediranib alone \\
\hline Han J et al (44) & Relapsed or refractory & 25 & Sunitinib alone \\
\hline Ready N et al (46) & Untreated ED & 18 & $\begin{array}{l}\text { Sunitinib combination chemo- } \\
\text { therapy }\end{array}$ \\
\hline Rudin CM et al (52) & Chemonaïve ED & 56 & $\begin{array}{l}\text { Carboplatin and etoposide with } \\
\text { or without oblimersen }\end{array}$ \\
\hline Kotsakis AP et al (57) & Previously treated relapsed & 40 & Everolimus alone \\
\hline Gandhi L et al (58) & Sensitive relapse & 23 & BI 2536 alone \\
\hline Heymach JV et al (59) & Sensitive relapse & 22 & R115777 alone \\
\hline
\end{tabular}

SCLC, small cell lung cancer; ED, extensive-stage disease; CR, complete response; PR, partial response.

patients received three immunizations. p53-specific $\mathrm{T}$ cell responses to vaccination were observed in $57.1 \%$ of patients. Immunological responses to vaccination were positively associated with a moderate increase in the titer of anti-adenovirus antibodies, and negatively with an accumulation of immature myeloid cells. One patient showed a clinical response to vaccination whereas most of the patients had disease progression. Clinical response to subsequent chemotherapy 
Table III. Studies in SCLC with promising results.

\begin{tabular}{|c|c|c|c|c|c|}
\hline Author (ref.) & Study population & Treatment & $\begin{array}{l}\text { No. } \\
\text { patients }\end{array}$ & $\begin{array}{c}\text { OS } \\
\text { (months) }\end{array}$ & Comments \\
\hline $\begin{array}{l}\text { Okamoto I } \\
\text { et al (15) }\end{array}$ & EGFR mutation & Gefitinib alone & 1 & Unknown & $\begin{array}{l}\text { Gefitinib effective in SCLCs } \\
\text { with EGFR mutation }\end{array}$ \\
\hline $\begin{array}{l}\text { Zakowski MF } \\
\text { et al (16) }\end{array}$ & EGFR mutation & Erlotinib or gefitinib alone & 1 & Unknown & $\begin{array}{l}\text { Erlotinib or gefitinib } \\
\text { effective in SCLCs with } \\
\text { EGFR mutation }\end{array}$ \\
\hline $\begin{array}{l}\text { Horn } \mathrm{L} \\
\text { et al }(35)\end{array}$ & Previously untreated ED & $\begin{array}{l}\text { Cisplatin plus etoposide } \\
\text { and bevacizumab }\end{array}$ & 63 & 10.9 & $\begin{array}{l}\text { Improved PFS and OS } \\
\text { relative to historical controls }\end{array}$ \\
\hline $\begin{array}{l}\text { Spigel DR } \\
\text { et al }(36)\end{array}$ & Previously untreated ED & $\begin{array}{l}\text { Bevacizumab vs. placebo } \\
\text { with cisplatin or carboplatin } \\
\text { plus etoposide }\end{array}$ & 52 & 9.4 vs. 10.9 & $\begin{array}{l}\text { Improved PFS, no } \\
\text { improvement in OS }\end{array}$ \\
\hline $\begin{array}{l}\text { Spigel DR } \\
\text { et al }(37)\end{array}$ & $\begin{array}{l}\text { ED patients with no prior } \\
\text { chemotherapy }\end{array}$ & $\begin{array}{l}\text { Irinotecan, carboplatin and } \\
\text { bevacizumab }\end{array}$ & 51 & 12.1 & $\begin{array}{l}\text { Warrant to further } \\
\text { randomized study }\end{array}$ \\
\hline $\begin{array}{l}\text { Ready NE } \\
\text { et al }(38)\end{array}$ & Untreated ED & $\begin{array}{l}\text { Cisplatin, irinotecan and } \\
\text { bevacizumab }\end{array}$ & 72 & 11.6 & $\begin{array}{l}\text { Improved PFS and OS } \\
\text { relative to historical controls }\end{array}$ \\
\hline $\begin{array}{l}\text { Vigano' MG } \\
\text { et al }(41)\end{array}$ & Relapsed & $\begin{array}{l}\text { NGR-hTNF and } \\
\text { doxorubicin }\end{array}$ & 28 & $3.2(\mathrm{PFS})$ & Further study is of interest \\
\hline $\begin{array}{l}\text { Gitlitz BJ } \\
\text { et al }(43)\end{array}$ & Platinum-treated ED & Sorafenib alone & 89 & $\begin{array}{l}\text { Sensitive, } 7 \\
\text { Refractory, } 5\end{array}$ & $\begin{array}{l}\text { Comparable with historical } \\
\text { controls receiving salvage } \\
\text { chemotherapy }\end{array}$ \\
\hline $\begin{array}{l}\text { Lubiner ET } \\
\text { et al }(45)\end{array}$ & First-line treatment of ED & $\begin{array}{l}\text { Irinotecan and carboplatin } \\
\text { followed by sunitinib }\end{array}$ & 34 & 7.6 (ТTP) & $\begin{array}{l}\text { Early assessment of activity } \\
\text { is encouraging }\end{array}$ \\
\hline $\begin{array}{l}\text { Rudin CM } \\
\text { et al }(54)\end{array}$ & Relapsed & ABT-263 alone & 39 & Ongoing & Acceptable safety \\
\hline $\begin{array}{l}\text { Langer CJ } \\
\text { et al }(55)\end{array}$ & ED & $\begin{array}{l}\text { Carboplatin and etoposide } \\
\text { with or without obatoclax }\end{array}$ & 155 & 10.6 vs. 9.9 & A trend for improved OS \\
\hline $\begin{array}{l}\text { Heist RS } \\
\text { et al }(56)\end{array}$ & Relapsed or refractory & $\begin{array}{l}\text { AT-101 combined with } \\
\text { topotecan }\end{array}$ & 36 & Ongoing & Warrant to further study \\
\hline
\end{tabular}

SCLC, small cell lung cancer; EGFR, epidermal growth factor receptor; ED, extensive-stage disease; PFS, progression-free survival; OS, overall survival.

was closely associated with the induction of immunological response to vaccination. This study provides clinical support for an emerging paradigm in cancer immunotherapy, wherein the optimal use of vaccination may be more effective, not as a separate modality, but in direct combination with chemotherapy (61).

$B e c 2$. Bec2 is an anti-idiotypic antibody that mimics GD3, a ganglioside that is expressed on the surface of tumor cells and is of neuroectodermal origin. A phase III study evaluated adjuvant vaccination with Bec2/bacille Calmette-Guerin in responsive patients with LD SCLC. Patients were randomly assigned to receive five vaccinations of Bec2 $(2.5 \mathrm{mg}) / \mathrm{BCG}$ vaccine or follow-up. The vaccination was administered over a 10 -week period. A total of 515 patients were randomly assigned. The primary toxicities of vaccination were transient skin ulcerations and mild flu-like symptoms. There was no improvement in survival, PFS or quality of life in the vaccination arm. The MST from randomization was 16.4 and 14.3 months in the observation and vaccination arms $(\mathrm{P}=0.28)$, respectively. Of the vaccinated patients, a trend toward prolonged survival was observed in those (one-third) who developed a humoral response $(\mathrm{P}=0.085)(62)$. Quality of life and symptom scores between the two treatment arms were not statistically different at any time (63).

\section{Discussion}

Targeted therapy drugs are widely used in NSCLC, but there are no targeted drugs approved for use in SCLC. Despite a number of clinical trials investigating SCLC, most of the trials yielded negative results (Tables I, II and III). Imatinib did not demonstrate clinical efficiency even in patients with c-kit expression, and the incidence of c-kit mutations in exons 9 and 11 was low. Vandetanib failed to demonstrate efficacy as a maintenance therapy for SCLC and cediranib failed to demonstrate objective responses in recurrent or refractory SCLC. The maintenance of sunitinib was well tolerated following 
platinum doublet chemotherapy as first-line treatment for ED SCLC, but did not demonstrate efficiency in relapsed or refractory SCLC. The combination of chemotherapy and sunitinib caused prolonged neutropenia and an unacceptable rate of treatment-related mortality, so it is not recommended. MMP inhibitors, including marimastat and BAY 12-9566, did not improve survival in SCLC. The combination of G3139 and chemotherapy did not improve any clinical outcome. BI 2536 and R115777 should not be assessed further as a single agent in SCLC.

Despite the low incidence of EGFR exon 19 or 21 mutation, an EGFR tyrosine kinase inhibitor may be effective for SCLC patients with EGFR exon 19 or 21 mutation. The biopsy taken for diagnosis may not accurately reflect the molecular features of SCLC, so more attention should be paid to the molecular mechanisms of SCLC. Further research should be undertaken to evaluate the feasibility of gefitinib in SCLC with EGFR exon 19 or 21 mutations. Angiogenesis may play an important role in SCLC and the results for thalidomide and bevacizumab are promising and need further clinical trials to evaluate efficiency and safety. Further study is warranted in sorafenib or NGR-hTNF in combination with chemotherapy. Further clinical trials concerning Bcl-2 inhibitors ABT-263, obatoclax and AT-101 are ongoing (54-56). Everolimus had limited single-agent antitumor activity in unselected previously treated patients with relapsed SCLC, and further evaluation in combination regimens for patients with sensitive relapsed SCLC may be considered. Further study of a vaccine is warranted.

It is important to seek effective targeted therapies to treat SCLC. Some patterns of gene expression or mutations may render targeted therapies for SCLC invalid. It is useful to classify SCLC by targeted genes. One targeted drug cannot be effective in all SCLC patients, while it may be effective in patients with a specific gene expression pattern or mutation. The low expression or mutation of a gene may have caused the negative results of some clinical trials. We should select suitable SCLC patients in further clinical trials by characterizing the targeted gene and the results of previous clinical trials including the promising results from subgroup analysis. Despite no targeted drugs being approved for use in SCLC, the results of trials on gefitinib, bevacizumab and Bcl-2 inhibitors are promising.

\section{Acknowledgements}

This study was funded by the Zhejiang Provincial Natural Science Foundation of China (no. Y2110004), the Zhejiang Province Medical Science Fund Project of China (nos. 2010KYA035, 2012KYB034 and 2012RCB004) and the Zhejiang Province Traditional Medical Science Fund Project of China (no. 2010ZA006).

\section{References}

1. Ferlay J, Shin HR, Bray F, et al: Estimates of worldwide burden of cancer in 2008: GLOBOCAN 2008. Int J Cancer 127: 2893-2917, 2010.

2. Govindan R, Page N, Morgensztern D, et al: Changing epidemiology of small-cell lung cancer in the United States over the last 30 years: analysis of the surveillance, epidemiologic, and end results database. J Clin Oncol 24: 4539-4544, 2006.

3. Patel AM, Dunn WF and Trastek VF: Staging systems of lung cancer. Mayo Clin Proc 68: 475-482, 1993.
4. Giroux DJ, Rami-Porta R, Chansky K, et al; International Association for the Study of Lung Cancer International Staging Committee: The IASLC Lung Cancer Staging Project: data elements for the prospective project. J Thorac Oncol 4: 679-683, 2009.

5. Hanna NH and Einhorn LH: Small-cell lung cancer: state of the art. Clin Lung Cancer 4: 87-94, 2002.

6. Hanna NH and Einhorn LH: Small cell lung cancer: treatment for extensive stage disease. In: Malignant Tumors of the Lung. Sculier JP and Fry WA (eds). Springer, New York, pp287-301, 2004.

7. Gridelli C, Perrone F and Monfardini S: Lung cancer in the elderly. Eur J Cancer 33: 2313-2314, 1997.

8. Mok TS, Wu YL, Thongprasert S, et al: Gefitinib or carboplatinpaclitaxel in pulmonary adenocarcinoma. N Engl J Med 361: 947-957, 2009.

9. Maemondo M, Inoue A, Kobayashi K, et al: Gefitinib or chemotherapy for non-small-cell lung cancer with mutated EGFR. N Engl J Med 362: 2380-2388, 2010.

10. Mitsudomi T, Morita S, Yatabe Y, et al: Gefitinib versus cisplatin plus docetaxel in patients with non-small-cell lung cancer harbouring mutations of the epidermal growth factor receptor (WJTOG3405): an open label, randomised phase 3 trial. Lancet Oncol 11: 121-128, 2010.

11. Rosell R, Gervais R, Vergnenegre A, et al; Spanish Lung Cancer Group: Erlotinib versus chemotherapy (CT) in advanced non-small cell lung cancer (NSCLC) patients (p) with epidermal growth factor receptor (EGFR) mutations: Interim results of the European Erlotinib Versus Chemotherapy (EURTAC) phase III randomized trial. J Clin Oncol 29 (Suppl): abstr 7503, 2011.

12. Zhou C, Wu YL, Chen G, et al: Erlotinib versus chemotherapy as first-line treatment for patients with advanced EGFR mutationpositive non-small-cell lung cancer (OPTIMAL, CTONG-0802): a multicentre, open-label, randomised, phase 3 study. Lancet Oncol 12: 735-742, 2011.

13. Douillard JY, Shepherd FA, Hirsh V, et al: Molecular predictors of outcome with gefitinib and docetaxel in previously treated non-small-cell lung cancer: data from the randomized phase III INTEREST trial. J Clin Oncol 28: 744-752, 2010.

14. Tanno S, Ohsaki Y, Nakanishi K, et al: Small cell lung cancer cells express EGFR and tyrosine phosphorylation of EGFR is inhibited by gefitinib ("Iressa", ZD1839). Oncol Rep 12: 1053-1057, 2004.

15. Okamoto I, Araki J, Suto R, et al: EGFR mutation in gefitinib responsive small-cell lung cancer. Ann Oncol 17: 1028-1029, 2006.

16. Zakowski MF, Ladanyi M and Kris MG; Memorial SloanKettering Cancer Center Lung Cancer OncoGenome Group: EGFR mutations in small-cell lung cancers in patients who have never smoked. N Engl J Med 355: 213-215, 2006.

17. Qian J, Qin SK, Tang QQ, et al: Gefitinib in patients with advanced refractory small cell lung cancer contemporaneous with superior vena cava syndrome. Chinese Clinical Oncology 10: 243-244, 2005.

18. Moore AM, Einhorn LH, Estes D, et al: Gefitinib in patients with chemo-sensitive and chemo-refractory relapsed small cell cancers: a Hoosier Oncology Group phase II trial. Lung Cancer 52: 93-97, 2006

19. Shiao TH, Chang YL, Yu CJ, et al: Epidermal growth factor receptor mutations in small cell lung cancer: a brief report. J Thorac Oncol 5: 195-198, 2011.

20. Tatematsu A, Shimizu J, Murakami Y, et al: Epidermal growth factor receptor mutations in small cell lung cancer. Clin Cancer Res 14: 6092-6096, 2008.

21. Lu HY, Sun WY, Chen B, et al: Epidermal growth factor receptor mutations in small cell lung cancer patients who received surgical resection in China. Neoplasma 59: 100-104, 2012.

22. Nicholson SA, Beasley MB, Brambilla E, et al: Small cell lung carcinoma (SCLC): a clinicopathologic study of 100 cases with surgical specimens. Am J Surg Pathol 26: 1184-1197, 2002.

23. Cirocchi R, Farinella E, La Mura F, et al: Efficacy of surgery and imatinib mesylate in the treatment of advanced gastrointestinal stromal tumor: a systematic review. Tumori 96: 392-399, 2010.

24. Reichardt P: Optimal use of targeted agents for advanced gastrointestinal stromal tumours. Oncology 78: 130-140, 2010.

25. Johnson BE, Fischer T, Fischer B, et al: Phase II study of imatinib in patients with small cell lung cancer. Clin Cancer Res 9: 5880-5887, 2003.

26. Krug LM, Crapanzano JP, Azzoli CG, et al: Imatinib mesylate lacks activity in small cell lung carcinoma expressing c-kit protein: a phase II clinical trial. Cancer 103: 2128-2131, 2005. 
27. Dy GK, Miller AA, Mandrekar SJ, et al: A phase II trial of imatinib (ST1571) in patients with c-kit expressing relapsed small-cell lung cancer: a CALGB and NCCTG study. Ann Oncol 16: 1811-1816, 2005.

28. Boldrini L, Ursino S, Gisfredi S, et al: Expression and mutational status of c-kit in small-cell lung cancer: prognostic relevance. Clin Cancer Res 10: 4101-4108, 2004.

29. Lu HY, Zhang G, Cheng QY, et al: Expression and mutation of the c-kit gene and correlation with prognosis of small cell lung cancer. Oncol Lett 4: 89-93, 2012.

30. Spigel DR, Hainsworth JD, Simons L, et al: Irinotecan, carboplatin, and imatinib in untreated extensive-stage small-cell lung cancer: a phase II trial of the Minnie Pearl Cancer Research Network. J Thorac Oncol 2: 854-861, 2007.

31. Schneider BJ, Kalemkerian GP, Ramnath N, et al: Phase II trial of imatinib maintenance therapy after irinotecan and cisplatin in patients with c-Kit-positive, extensive-stage small-cell lung cancer. Clin Lung Cancer 11: 223-227, 2010.

32. Pujol JL, Breton JL, Gervais R, et al: Phase III double-blind, placebo-controlled study of thalidomide in extensive-disease small-cell lung cancer after response to chemotherapy: an intergroup study FNCLCC cleo04 IFCT 00-01. J Clin Oncol 25: 3945-3951, 2007.

33. Arnold AM, Seymour L, Smylie M, et al; National Cancer Institute of Canada Clinical Trials Group Study BR.20: Phase II study of vandetanib or placebo in small-cell lung cancer patients after complete or partial response to induction chemotherapy with or without radiation therapy: National Cancer Institute of Canada Clinical Trials Group Study BR.20. J Clin Oncol 25: 4278-4284, 2007.

34. Spigel DR, Hainsworth JD, Farley C, et al: Tracheoesophageal (TE) fistula development in a phase II trial of concurrent chemoradiation (CRT) and bevacizumab (B) in limited-stage small-cell lung cancer (LS-SCLC). J Clin Oncol 26 (Suppl): abstr 7554, 2008 .

35. Horn L, Dahlberg SE, Sandler AB, et al: Phase II study of cisplatin plus etoposide and bevacizumab for previously untreated, extensive-stage small-cell lung cancer: Eastern Cooperative Oncology Group Study E3501. J Clin Oncol 27: 6006-6011, 2009.

36. Spigel DR, Townley PM, Waterhouse DM, et al: Randomized phase II study of bevacizumab in combination with chemotherapy in previously untreated extensive-stage small-cell lung cancer: results from the SALUTE trial. J Clin Oncol 29: 2215-2222, 2011.

37. Spigel DR, Greco FA, Zubkus JD, et al: Phase II trial of irinotecan, carboplatin, and bevacizumab in the treatment of patients with extensive-stage small-cell lung cancer. J Thorac Oncol 4: 1555-1560, 2009.

38. Ready NE, Dudek AZ, Pang HH, et al: Cisplatin, irinotecan, and bevacizumab for untreated extensive-stage small-cell lung cancer: CALGB 30306, a phase II study. J Clin Oncol 29 4436-4441, 2011.

39. Waterhouse DM, Morgan SK, Spigel DR, et al: Phase II study of oral topotecan plus bevacizumab (topo-bev) for second-line treatment of small cell lung cancer (SCLC). J Clin Oncol 28 (Suppl): abstr 7055, 2010

40. Jalal S, Bedano P, Einhorn L, et al: Paclitaxel plus bevacizumab in patients with chemosensitive relapsed small cell lung cancer: a safety, feasibility, and efficacy study from the Hoosier Oncology Group. J Thorac Oncol 5: 2008-2011, 2010.

41. Vigano' MG, Cavina R, Novello S, et al: Phase II trial of NGR-hTNF and doxorubicin in relapsed small cell lung cancer (SCLC). J Clin Oncol 29 (Suppl): abstr 7077, 2011.

42. Ramalingam SS, Belani CP, Mack PC, et al: Phase II study of Cediranib (AZD 2171), an inhibitor of the vascular endothelial growth factor receptor, for second-line therapy of small cell lung cancer (National Cancer Institute \#7097). J Thorac Oncol 5: 1279-1284, 2010

43. Gitlitz BJ, Glisson BS, Moon J, et al: Sorafenib in patients with platinum (plat) treated extensive stage small cell lung cancer (E-SCLC): A SWOG (S0435) phase II trial. J Clin Oncol 26 (Suppl): abstr 8039,2008

44. Han J, Lim KY, Kim HY, et al: Phase II study of sunitinib in patients with relapsed or refractory small cell lung cancer (SCLC). J Clin Oncol 29 (Suppl): abstr 7084, 2011.

45. Lubiner ET, Spigel DR, Greco FA, et al: Phase II study of irinotecan and carboplatin followed by maintenance sunitinib in the first-line treatment of extensive-stage small cell lung cancer. J Clin Oncol 28 (Suppl): abstr 7049, 2010
46. Ready N, Dunphy F, Pang H, et al: Combination chemotherapy with sunitinib (IND 74019; NSC 736511) for untreated extensivestage small cell lung cancer (SCLC): CALGB 30504 phase IB safety results. J Clin Oncol 28 (Suppl): abstr 7056, 2010.

47. Michael M, Babic B, Khokha R, et al: Expression and prognostic significance of metalloproteinases and their tissue inhibitors in patients with small-cell lung cancer. J Clin Oncol 17: 1802-1808, 1999.

48. Shepherd FA, Giaccone G, Seymour L, et al: Prospective, randomized, double-blind, placebo-controlled trial of marimastat after response to first-line chemotherapy in patients with small-cell lung cancer: a trial of the National Cancer Institute of Canada-Clinical Trials Group and the European Organization for Research and Treatment of Cancer. J Clin Oncol 20: 4434-4439, 2002.

49. Rigas JR, Denham CA, Rinaldi D, et al: Adjuvant targeted therapy in unresectable lung cancer: the results of two randomized placebo controlled trials of BAY 12-9566, a matrix metalloproteinase inhibitor (MMPI). Lung Cancer 41 (Suppl 2): S34 (abstr O107), 2003.

50. Rudin CM, Otterson GA, Mauer AM, et al: A pilot trial of G3139, a bcl-2 antisense oligonucleotide, and paclitaxel in patients with chemorefractory small-cell lung cancer. Ann Oncol 13: 539-545, 2002.

51. Rudin CM, Kozloff M, Hoffman PC, et al: Phase I study of G3139, a bcl-2 antisense oligonucleotide, combined with carboplatin and etoposide in patients with small-cell lung cancer. J Clin Oncol 22: 1110-1117, 2004

52. Rudin CM, Salgia R, Wang X, et al: Randomized phase II study of carboplatin and etoposide with or without the bcl-2 antisense oligonucleotide oblimersen for extensive-stage small-cell lung cancer: CALGB 30103. J Clin Oncol 26: 870-876, 2008.

53. Shoemaker AR, Mitten MJ, Adickes J, et al: Activity of the Bcl-2 family inhibitor ABT-263 in a panel of small cell lung cancer xenograft models. Clin Cancer Res 14: 3268-3277, 2008.

54. Rudin CM, Oliveira MR, Garon EB, et al: A phase IIa study of ABT-263 in patients with relapsed small-cell lung cancer (SCLC). J Clin Oncol 28 (Suppl): abstr 7046, 2010.

55. Langer CJ, Albert I, Kovacs P, et al: A randomized phase II study of carboplatin $(\mathrm{C})$ and etoposide $(\mathrm{E})$ with or without pan-BCL-2 antagonist obatoclax $(\mathrm{Ob})$ in extensive-stage small cell lung cancer (ES-SCLC). J Clin Oncol 29 (Suppl): abstr 7001, 2011

56. Heist RS, Fain J, Chinnasami B, et al: A phase I/II (P1/P2) study of AT-101 in combination with topotecan (T) in patients with relapsed or refractory small cell lung cancer (SCLC) after prior platinum-containing first-line chemotherapy. J Clin Oncol 27 (Suppl): abstr 8106, 2009.

57. Kotsakis AP, Tarhini A, Petro D, et al: Phase II study of RAD001 (everolimus) in previously treated small cell lung cancer (SCLC). J Clin Oncol 27 (Suppl): abstr 8107, 2009.

58. Gandhi L, Chu QS, Stephenson J, et al: An open label phase II trial of the Plk1 inhibitor BI 2536, in patients with sensitive relapse small cell lung cancer (SCLC). J Clin Oncol 27 (Suppl): abstr 8108, 2009.

59. Heymach JV, Johnson DH, Khuri FR, et al: Phase II study of the farnesyl transferase inhibitor R115777 in patients with sensitive relapse small-cell lung cancer. Ann Oncol 15: 1187-1193, 2004.

60. Hamada M, Fujiwara T, Hizuta A, et al: The p53 gene is a potent determinant of chemosensitivity and radiosensitivity in gastric and colorectal cancers. J Cancer Res Clin Oncol 122: 360-365, 1996.

61. Antonia SJ, Mirza N, Fricke I, et al: Combination of p53 cancer vaccine with chemotherapy in patients with extensive stage small cell lung cancer. Clin Cancer Res 12: 878-887, 2006.

62. Giaccone G, Debruyne C, Felip E, et al: Phase III study of adjuvant vaccination with Bec2/bacille Calmette-Guerin in responding patients with limited-disease small-cell lung cancer (European Organisation for Research and Treatment of Cancer 08971-08971B; Silva Study). J Clin Oncol 23: 6854-6864, 2005.

63. Bottomley A, Debruyne C, Felip E, et al: Symptom and quality of life results of an international randomised phase III study of adjuvant vaccination with $\mathrm{Bec} 2 / \mathrm{BCG}$ in responding patients with limited disease small-cell lung cancer. Eur J Cancer 44: 2178-2184, 2008 